Int. J. Electrochem. Sci., 11 (2016) $9019-9029$

\title{
One-step Synthesis of Spherical Polyaniline/Graphene Composites by Microemulsion for Supercapacitors
}

\author{
Pengfei Zhu, Tao Yu, Shaohong Kang, Shiyou Guan* \\ School of Materials Science and Engineering, East China University of Science and Technology, Mei \\ Long Road 130, Shanghai 200237, P.R. China \\ *E-mail: syguan@ecust.edu.cn
}

doi: $10.20964 / 2016.11 .29$

Received: 16 July 2016 / Accepted: 2 September 2016 / Published: 10 October 2016

\begin{abstract}
A simple approach to achieve microspherical polyaniline/graphene (PANI/rGO) composites by microemulsion has been developed, and the composites are further used as electrode materials for supercapacitors. Compared to other methods, microemulsion polymerization is a thermodynamically stable and easy-processing method, where the formed micelles act as "soft templates" to form the stable morphologies according to the type and concentration of surfactants. The one-step process is that water-dispersible GO is directly added into the SDS micelles during the microemulsion polymerization. The spherical SDS micelles just attach on the GO nanosheets with large lateral size, while the small GO nanosheets may embed into internal of the micelles. So, the as-prepared PANI/rGO composites have two probable ideal structures. Due to their unique architecture and the synergistic effect between PANI and graphene, the as-prepared PANI/rGO composites show the maximum electrochemical capacity of $495.9 \mathrm{~F} \mathrm{~g}^{-1}$ at $0.5 \mathrm{~A} \mathrm{~g}^{-1}$, excellent rate capability and improved cycling stability.
\end{abstract}

Keywords: polyaniline microspheres; microemulsion; graphene; supercapacitors.

\section{$\underline{\text { FULL TEXT }}$}

(C) 2016 The Authors. Published by ESG (www.electrochemsci.org). This article is an open access article distributed under the terms and conditions of the Creative Commons Attribution license (http://creativecommons.org/licenses/by/4.0/). 